\title{
The Food Policy Audit: A new tool for community food system planning
}

Jennifer O’Brien, a,* Urban and Environmental Planning, University of Virginia

Tanya Denckla Cobb, ${ }^{\mathrm{b}}$ Institute for Environmental Negotiation and Department of Urban and Environmental Planning, University of Virginia

Submitted 7 June 2011 / Revised 19 January 2012 and 20 March 2012 / Accepted 20 March 2012 / Published online 14 June 2012

Citation: O'Brien, J., \& Denckla Cobb, T. (2012). The Food Policy Audit: A new tool for community food system planning. Journal of Agriculture, Food Systems, and Community Development, 2(3), 177-191. http://dx.doi.org/10.5304/jafscd.2012.023.002

Copyright (C) 2012 by New Leaf Associates, Inc.

\begin{abstract}
The Food Policy Audit was developed in response to the growing need for tools to assist in the food planning process and was piloted in a graduate urban and environmental planning course at the University of Virginia. The audit proceeded in two phases: phase one consisted of 113 yes-or-no research questions regarding the existence of foodbased policy relating to public health, economic development, environmental impacts, social equity, and land conservation; phase two confirmed the validity of phase one's results through a series of
\end{abstract}

\footnotetext{
a Jennifer O'Brien is an Urban and Environmental Planning graduate student at the University of Virginia.

* Corresponding author: Jennifer O’Brien, 4998 Break Heart

Road, Crozet, VA 22932 USA; +1-313-303-6244;

jen.obrien3@gmail.com

Tanya Denckla Cobb is Associate Director at the Institute for Environmental Negotiation, and lecturer with the Department of Urban and Environmental Planning at the University of Virginia.

Tanya Denckla Cobb, Institute for Environmental Negotiation, 2015 Ivy Road, P.O. Box 400179, Charlottesville, VA 22904 USA; +1-434-924-1855; td6n@,virginia.edu
}

stakeholder meetings. The meetings also provided insight into the success of policies and initiatives currently in place, community attitudes and perceptions, and community priorities for moving forward. The Food Policy Audit process proved educationally beneficial to both students and community members, and provided a policy-based tool for communities interested in shaping a more sustainable and resilient food system.

\section{Keywords}

audit, food policy, food system curriculum, food system planning, local food, local food policy, planning tool, sustainable food system, planning policy

\section{The Food Policy Audit: Development and Trial Run}

To enhance the array of twenty-first century community planning tools, such as GIS mapping, modeling, and data analysis, University of Virginia faculty developed a Food Policy Audit in the fall of 2009 , and conducted a pilot audit of a five-county region of central Virginia with a graduate planning class in the spring of 2010. The audit serves several functions: raising community awareness and under- 
standing of how food system issues interplay with a host of other community issues; beginning a community conversation about its food system priorities; and providing a baseline inventory and gap analysis of formal and informal policies affecting the community food system.

\section{Emerging Need for New Planning Tools}

Whatever the dominant issue of the day, food is inherently linked to public, environmental, and economic health, and plays an important role in a community's quality of life. Production and distribution of edible goods was a primary concern of early U.S. urban planners such as Ebenezer Howard, Lewis Mumford, and Patrick Geddes. As early as 1890 , each of these men advocated for comprehensive regional planning that included provisions for the production, transportation, distribution, and consumption of food. However, as a result of industrialization, rapid development of transportation modes and networks, and the proliferation of urban sprawl, the twentieth century saw food fall off the modern urban planning agenda. Rather than playing a fundamental role in a community vision, food and agricultural issues became an afterthought to transportation, zoning, housing, and land conservation matters.

While food took a backseat in the world of planning, it persisted as a subject of national concern - be it in an economic, social, environmental or health context. During the second half of the twentieth century, the consequences of contemporary methods of food production, distribution, and consumption began to emerge on the national agenda through the lenses of environmental and social justice. In the 1960s, Rachel Carson's Silent Spring (1962) exposed the environmental impacts of food production, launching the environmental movement, while a decade later Frances Moore Lappé's Diet for a Small Planet (1971) exposed the problem of global hunger as one of distribution rather than production. The oil embargo of 1973 brought to public attention the danger of depending on long-distance transportation systems to supply a basic need such as food (Pothukuchi \& Kaufman, 1999). The 1980s featured the first Farm Aid concert, which raised awareness of the hardship that small farmers were experiencing as industrial agriculture replaced traditional systems. Robert Rodale nurtured the organic movement from the 1950s through the 1980s through publications from the Rodale Press and on-farm research by the Rodale Institute. Organic products finally entered the mainstream American market during the 1990s (Fromartz, 2006), with the creation and success of organic retailers such as Whole Foods and Wild Oats.

Today, the widely publicized obesity epidemic and increasing rates of diabetes have moved the twenty-first century food spotlight onto health, specifically in the areas of access to and availability of fresh, nutritious food. The general public has embraced books such as Michael Pollen's

Omnivore's Dilemma (2006) and movies such as Food, Inc. (2008) that highlight the unintended and detrimental environmental, social, and healthrelated consequences of our current food system. First lady Michelle Obama has become a fervent advocate for a complete overhaul of childhood nutrition programs throughout the country. The alarmingly high rate of Americans experiencing obesity and nutrition-related medical problems has forced food and nutrition into the national spotlight. The statistics are compelling: the U.S. Centers for Disease Control and Prevention estimates that one in every three children in the United States is either overweight or obese, with an even higher rate among African Americans, Hispanics, and Native Americans. Of Americans ages 17 to 25,27 percent are too overweight to join the military (Christeson, Taggart, \& MessnerZidell, 2010), and nearly $\$ 120$ billion is spent every year to treat obesity-related conditions (Wolf \& Colditz, 1998). In 1999 urban planning professors Kameshwari Pothukuchi and Jerome Kaufman asked whether it would take a crisis to bring food systems to the forefront of the national urban policy agenda (Pothukuchi, 1999), and it appears that the obesity epidemic is providing that platform. As the relationship between public health and the food environment has become more widely understood, urban planners and planning institutions have slowly begun reintroducing food security issues into their agendas and curricula. In recognition of food as a subject for serious planning consideration, the American Planning 
Association released a policy guide on community and regional food planning in 2007 (APA, 2007).

This marked the official re-introduction of the food system into the planner's purview and reiterated the fundamental role it plays in a sustainable and resilient community.

\section{The Role of the Food System Assessment}

Several communities have taken innovative steps to improve their food systems. The creation of food security focus groups, community food forums and food policy councils began as early as the 1980s. There are currently over 100 documented food policy councils in the nation, some appointed by city councils or governors, and some regionally self-formed as nongovernmental nonprofits. All are constituted with representation from the broad spectrum of stakeholder interests in food policy, such as agriculture, farmland preservation, economic development, environmental protection, education, and community health and nutrition. These councils offer a way for very different interest groups to come together to discover, identify and advocate for a common cause. Groups which might not otherwise have occasion to interact — such as kindergarten through high school educators and farmland preservationists, or public health advocates and farmers - are educating each other about complex constituent programs and needs relating to food production, distribution and consumption. One of the first steps taken by these grassroots groups is an assessment that documents and analyzes the community's food assets, gaps, opportunities and challenges (Pothukuchi, 1999). In some cases, the process is reversed, with a food system assessment prompting the creation of a food policy council.

Regardless of the method of inception, food assessments have proven to be powerful tools for identifying disparities in community resources and raising community awareness of food access issues. By prompting citizens to examine their food environment, an assessment opens a public dialog that is grounded in the realities of existing community resources. Assessments typically address practical aspects of the community food system production, distribution, and consumption - in addition to community resilience and welfare. Such issues require knowledge of the community's emergency food system and safety net, the affordability and availability of nutritious food, and the physical ease of accessing food through affordable modes of transportation.

Food system assessments vary in scope and complexity. In a 1994 study of six food policy councils, Kenneth Dahlberg, professor of political science at Western Michigan University, wrote that a comprehensive food policy should include "production issues (farmland preservation, farmers' markets, household and community gardens), to processing issues (local vs. external), to distribution issues (transportation, warehousing) to access issues (inner-city grocery stores, co-ops, school breakfasts and lunches, food stamps, the WIC program, etc.), to use issues (food safety and handling, restaurants, street vendors), to food recycling (gleaning, food banks, food pantries and soup kitchens) to waste stream issues (composting, garbage fed to pigs, etc.)" (Dahlberg, 1994, p. 3). Another step forward in developing an appropriate scope for a food system assessment came in 2002 when the USDA created a Community Food Security Assessment Toolkit, building on the 1999 Community Food Security Assessment Conference sponsored by the Economic Research Service (ERS). This toolkit compiled the experiences of food policy councils throughout the country in an effort to create a standardized, comprehensive assessment tool. In addition to outlining how to go about gathering this data, the USDA advocated that a food system assessment should include six basic components: a profile of community socioeconomic and demographic characteristics; a profile of community food resources; assessments of household food insecurity; food resource accessibility and affordability; and community food production (Cohen, 2002).

Food assessments have been successful in raising awareness of food access and quality issues by involving a variety of stakeholders in an assetbased, collaborative approach. Assessments tap into a community's experience and culture by engaging the public in all phases of the process: planning stages, research completion, as well as identifying and achieving goals. According to the Community Food Security Coalition's report, 
What's Cooking in Your Food System: A Guide to Community Food Assessment, "emphasis on building local capacity and social capital, rather than simply gathering data about community needs or problems also enhances its sustainability" (Pothukuchi, Joseph, Burton, \& Fisher, 2002, p. 13). As a result of this emphasis on building community capacity, food system assessments can be a force for community change by identifying existing community resources and future needs. While any positive change in a community's system of food production, distribution, and access might be considered a victory, the ultimate goal for planners is to facilitate a supportive community framework for ongoing growth and development. One key to building this framework is to ensure that a community's laws, policies, and zoning ordinances enable, rather than stifle, this growth and development.

In addition to federal and state laws and policies, local regulations play a major role in determining where food is grown, sold, and consumed. The web of formal and informal policies affecting these issues can be difficult to uncover and examine. This is the point where urban planning techniques can provide significant benefits to communities carrying out food system assessments. Through a planning lens, a food system assessment highlights the effects of the built environment, as well as the policies that create this environment. A study of nine food system assessments (four of which were led by professionals with planning backgrounds) led Pothukuchi to conclude that planner-led food assessments were more inclined to incorporate options for local government intervention, display a more thorough understanding of community concerns, utilize spatial mapping as an analysis tool, and distribute findings to a larger audience (Pothukuchi, 2004). Incorporating planning-specific skills into food assessments can create more comprehensive, compelling reports-precisely the type of information needed to facilitate change at the government level.

More recently, Freedgood, Pierce-Quiñonez, and Meter reviewed the "growing body of assessment tools" and created a useful framework that characterizes the different methodologies of these assessment tools (2011, p. 83). They identify eight distinct assessments: foodshed, community food system, community food security, community food asset, food desert, land inventory, local food economy, and local food industry. Each approach is characterized by its purpose, methodology, and limitations, and specific examples are provided. Local policy clearly plays a role in each of these assessments, providing the backdrop for the conditions that are being assessed, from land use to food security. Each assessment approach implicitly or explicitly assumes that policies may either support or serve as a barrier for an equitable and sustainable local food system. Some take an asset-based approach, while others assess community needs or specific impacts, such as access, hunger, or public health. Some employ mapping, inventories, and community engagement. While Freedgood, PierceQuiñonez, and Meter are careful to note that the food planning field is rapidly evolving, and therefore their review may not be comprehensive, they have created a valuable way of differentiating and categorizing the emerging tools. Yet it appears that not one of these tools or approaches helps a community to more effectively use its assets, address needs, and reduce undesired impacts by laying out a full array of potentially desirable policies for the community to examine and prioritize. This gap in planning tools is what the Food Policy Audit is designed to fill.

\section{Creating an Assessment Tool Specifically for Policy Change}

Tim Beatley and Tanya Denckla Cobb were coteaching a food systems planning course in the Department of Urban and Environmental Planning at the University of Virginia, in Charlottesville, when they set out to confront the need for a more targeted food assessment. The spring 2010 class was the second in a series of three Community Food System courses, with the first focusing on assessing food environments, the second on policy, and the third on global/local connections. In previous semesters, students had conducted a variety of studies, including a preliminary food assessment of the five-county Thomas Jefferson Planning region; evaluations of specific players in the local food system (restaurants, farms, institutions, a food bank) and the policies influencing their practices; an analysis of global sources and 
inputs into different parts of the local food system; and an evaluation of the ability of the five-county region to feed itself based on farm production and available processing facilities.

The policy-focused portion of the course cycle came at an opportune time, just as Albemarle County (of which Charlottesville is the county seat) was beginning to grapple with policy related to roadside farm stands. Grassroots efforts to improve local food access throughout the region had been accelerating in recent years, and had reached the tipping point of policy creation. A new nonprofit, the Local Food Hub, was providing distribution services for local farmers to aggregate and sell their produce to larger institutions. The region's land conservation nonprofit, the Piedmont Environmental Council, had spearheaded Virginia's first "Buy Fresh, Buy Local" (BFBL) guide, and then had been named the state's BFBL lead agency. A citizen-led group, Market Central, was beginning to seek a permanent year-round shelter for the Charlottesville farmers' market. A regional nonprofit, the Jefferson Area Board for Aging (JABA), had set - and quickly met - an ambitious goal of improving the thousands of meals it serves to seniors each month by purchasing at least 20 percent of the ingredients from local farmers. University students were requesting more locally sourced foods in cafeterias and were gaining a favorable audience with administrators of the campus food service provider. One campus café had been reconfigured specifically to serve locally sourced foods.

Throughout Charlottesville's five-county region, organizations were attempting to increase awareness of local food issues. Without a comprehensive analysis it was unclear how much progress was being made, or what might be needed to enable further progress. In an effort to gauge the region's progress and better understand the region's food environment, the team made up of Denckla Cobb, Beatley, and teaching assistant Jessica Ray decided to create a formal Food Policy Audit (FPA). The FPA would build upon the strengths of community food assessments and guide users through the complicated process of uncovering local, regional and federal policies relevant to a local food system. The hope was to create a tool that would be broadly useful to communities throughout the nation. The team sought to construct a tool that was accessible for use by college students, community nonprofits, and citizens leaders, but also sufficiently detailed to provide meaningful guidance to professional planners and community decision-makers.

To begin, the team decided to make the FPA as objective as possible, modeling it after an energy audit that consists of a series of simple "yes-or-no" questions. The team also reviewed the literature for related tools and audits, in hope of building on the work of others. The first draft of the FPA consisted of 101 questions regarding the existence and content of policies influencing food production, sale, and consumption. Questions were culled from a variety of resources and divided into five topical sections. Many questions were influenced by the goals and initiatives of the Prevention Institute, a national nonprofit that promotes policies, organizational practices, and collaborative efforts intended to improve health and quality of life. Other resources included Public Health Law and Policy, the Community Food Security Coalition, the Virginia Farm to School Program, the North American Food Policy Council, the Virginia Department of Agriculture and Consumer Services, and the American Farmland Trust.

Questions were collected, edited, and refined. The list needed to be presented in a manner that planners would find user-friendly during the audit process, as well as valuable when reporting the findings to the community. Rather than organizing the questions according to components of a food system (i.e., food production, distribution, and access), the team decided to frame the questions according to five key concerns that community decision-makers face every day. The key concerns are public health, economic development, environmental impacts, social equity, and land conservation (including access to land for food production). Throughout the five categories, the audit investigates the presence of policies that reduce and prevent community obesity and chronic illness, provide transportation options to food markets and stores, or reduce community exposure to pesticides and chemicals in food. Some audit questions try to discern a policy through the 
presence of an amenity, such as, "Do safe biking and walking paths exist between neighborhoods and food stores and markets?" Other questions discern a policy more directly, such as "Does the locality have a policy to support land conservation for food production?" While the draft audit seemed long at 101 questions, the team agreed that during this initial phase of development, the audit should err on the side of too many rather than too few questions.

Framing the audit questions in the simple "yes" or "no" format was a key decision. Beatley made a compelling argument that this would objectify the results, reducing room for error and minimizing argument. Either a policy exists or it does not. The audit method requires the auditor to document and cite the location of an existing policy, while minimizing the opportunity for the auditor to inject personal opinion or bias on how well the community is enforcing the policies.

On the other hand, the team also recognized that simply documenting the presence of community policies would not produce a useful audit. While a policy might exist on the books, such as a goal to support a county's rural farm character, aspects of the zoning code may be inadvertently preventing the policy from being implemented. Conversely, while a policy to increase access to affordable, healthy food might not exist in the books, the community could be making great strides in this area by providing Electronic Benefit Transfer (EBT) access at farmers' markets. EBT is an electronic system that allows participants to transfer funds from the federal Supplemental Nutrition Assistance Program (SNAP) to a retailer. The team wanted to design an audit that would be more than a simple inventory of a community's existing legal infrastructure. In a report separate from the initial, objective research, the audit would also reflect the community's informal food policy structure and the reality of what was or was not happening on the ground.

Ultimately, the team designed the Food Policy Audit to have two distinct implementation phases. Completing the audit questions in phase one would provide a preliminary picture of the community through the information provided in laws, plans, and documented regulations. A second phase of eliciting community knowledge would provide the additional information necessary to round out and perhaps even radically change the picture.

\section{Engaging the Community}

Before the FPA could be tested, a key step in developing this tool was to engage the community in reviewing and contributing to the draft audit questions. Early engagement of key stakeholders would provide important feedback to help craft a tool that would be truly useful. Over the space of several months, Denckla Cobb and Ray met with community stakeholders to share the draft audit and gather suggestions and feedback on questions such as $W$ as the audit even a good idea? If answered, would the audit questions provide information useful to decision-makers? Were any questions irrelevant, duplicative, or could some questions be phrased in a better way? Were there additional questions that should be included in the audit? Regional organizations that were involved in various aspects of the food system were consulted: the community's Obesity Task Force, the regional Planning District Commission, the UVA Health System Nutrition Services, a school system nutritionist, a legal aid advocate for migrant workers, a nonprofit agency serving a low-income neighborhood that was managing the area's first urban farm, and the region's nonprofit agency serving seniors. During these conversations, Ray and Denckla Cobb not only received numerous suggestions for wordsmithing, but also learned of additional substantive community concerns. These issues were transformed into additional audit questions, and the audit grew to include 113 questions.

\section{Preparing To Test the Audit on a Five-County Region}

Beatley and Denckla Cobb's 2010 Food System Planning course, offered in the graduate urban and environmental planning program, undertook a semester-long project to pilot the FPA in the city of Charlottesville and the surrounding five-county region. The audit proceeded in two phases. In phase one, students were divided into teams of three, with each team assigned to one of six localities (the city and five counties). Within the team, students took on responsibility for different substantive portions of the audit. Students first gathered all the relevant planning and policy 
documents for their assigned locality, including comprehensive plans, strategic plans, school wellness plans, zoning ordinances, regional and state guidelines, and school district strategic plans. Upon reviewing each document, students answered relevant audit questions with a "yes" or "no," and provided excerpts and citations of pertinent information from the document.

In phase two, students met with various members of the community to share their findings and obtain feedback and insight. These community members had already been approached by the team, briefed on the project, and agreed to meet with students. Through the community conversations, students were able to "groundtruth" their audit, learning whether the locality's policy infrastructure reflected what was actually happening. Students were required to meet with at least five different organizations or people, two of whom had to be from local government. It was important for students to interview people working in different sectors in order to obtain diverse perspectives on the community's food system, factors helping or hindering its progress, and community needs and priorities.

To prepare students for phase two, the faculty team conducted training in community engagement techniques, and students spent time role-playing possible conversations and situations. Students were encouraged to go into their community meetings with an attitude of openness and inquiry, be prepared for surprises, and learn from the stakeholders. In this same vein, students were instructed not to go into their community meetings with any assumptions about specific stakeholders, policies, or activities on the ground, regardless of their considerable research on the locality. This training was an important part of the process that benefited both the experience of the community participants and quality of the audit. It was imperative that the meetings in phase two did not become a forum for students to attempt to solve problems, but instead to serve to confirm the validity of the yes-or-no portion of the audit, enrich student understanding of the informal policy infrastructure, and elicit community members' food systems priorities.

\section{Conducting and Evaluating the Test Run}

The completed audits highlighted some general trends throughout the region, as well as countyspecific issues. The city of Charlottesville and Albemarle County had more advanced food system policies and initiatives than the more rural counties of Fluvanna, Greene, Nelson, and Louisa. Presumably, this was because of increased population, budgets, and local government capacity. The more rural counties tended to have less documented foodrelated policy, yet face-to-face interviews revealed numerous grassroots initiatives, such as farmers' markets, gleaning, and local buying programs. These rural counties also revealed a common interest in economic development through increased production and processing facilities, as well as food- and wine-based tourism.

Childhood nutrition was a major concern for all localities, fueled by the National School Lunch Program and state requirements for school wellness plans and councils. School officials in each district mentioned the need for more time and money for local produce purchasing and menu planning. Each district had also participated in Virginia's Farm to School Week in some capacity, with the help of the Local Food Hub, a nonprofit that provides distribution services for area farmers. The Local Food Hub was a strength identified in many localities, in addition to the work being carried out by the region's advocacy organization for seniors, JABA. A strong interest in the agricultural heritage of the region and a strong sense of community were also identified as strengths in most localities.

Opportunities identified by community members included connecting the goals of local economic development boards with the work of the Local Food Hub and JABA, and increasing the coordination between existing food security organizations. In every locality, stakeholders indicated that increasing local food purchasing was a priority, particularly within schools. Increasing education on agricultural and nutritional topics were priorities in five out of six localities. In the more rural counties, stakeholders felt that food initiatives were often hampered by broader community development issues, such as a lack of communication infrastructure. A broadband 
network is not available in Nelson County, which limits farms' and businesses' access to consumer markets. On the other hand, localities with well developed communication infrastructure had more advanced food-specific priorities. For example, the city of Charlottesville's community priority list included, "Encourage the Charlottesville-Albemarle Technical Education Center (CATEC) programs to include an agricultural track to support new and beginning farmers," and Albemarle County's included, "Provide a land-use taxation break for farms under 5 acres $[2 \mathrm{ba}$."

In localities with more active food system initiatives, the step of identifying stakeholder priorities turned out to be particularly important. A variety of grassroots efforts had already proved successful, so streamlining stakeholder goals into a set of common priorities would allow the various efforts to move forward together, rather than in isolation.

\section{Promising Findings}

The audit's question-based format fostered an interesting give-and-take process between community members and students. Participants were often surprised by the range of issues that were included under the umbrella of a community food system. Students found that audit questions prompted community members to think about a program or policy in a new way, indicating that they hadn't previously considered that program or policy in the context of their community's food system. For example, some people hadn't thought about the relevance of safe walking and biking paths in the context of enabling safe access to food, or the importance of adjusting a local transportation plan to enable easier access to groceries via public transit. For some, consideration of migrant farm labor was an important addition to their conceptualization of the local food system, triggered by the audit questions regarding adequate training in pesticide management and provision of protective gear, as well as access to fresh, healthy foods for migrant farm laborers. Through the community engagement phase, conversations with community participants revealed that a major benefit of the audit was simply raising community awareness of the complexity and importance of the local food environment.

Additionally, students specifically asked participants about their challenges and ideas for improving their local food system. These questions elicited new insights and ideas, and even created motivation for later action.

One such instance arose from the questions regarding migrant farm workers during the Greene County audit. A social equity audit question asked, "Does the locality provide or ensure that adequate protection against pesticides is provided to farm workers?" Some participants responded that their community did not have any migrant laborers. This response provided students with insight into the community's understanding of local farming practices. While the county does not experience a large influx of migrant workers, the complete lack of awareness of their presence signaled a disconnect between county residents' perceptions and the reality of the labor force. The presence of migrant farm laborers had been confirmed during an earlier meeting with Virginia Cooperative Extension staff, and the students shared these findings. This new information prompted the community participants to devise ways in which existing food assistance programs could benefit local migrant laborers, and ways in which local policies were currently benefitting or complicating the food environment for this particular population. Through this exchange, stakeholders and students realized the importance of gaining a thorough understanding of existing conditions prior to selecting a policy approach. Without an accurate perception or awareness of the problems facing a locality, it would be difficult, if not impossible, to develop appropriate solutions. In this instance, the audit was an objective tool that raised community awareness about a previously unidentified county issue, educated the community about its own food system, and provided the community with a starting point for exploring appropriate solutions.

Both phases of the audit — research and community engagement - proved essential. The research phase laid the groundwork for community engagement that was both informed and targeted. For example, the students audits did confirm that all schools had developed a comprehensive well- 
ness policy, as mandated by the Child Nutrition and WIC Reauthorization Act of 2004, and that all included nutrition guidelines, vending machine regulations, and physical education standards. But student research also revealed that some counties had gone further than required by following the Virginia Action for Healthy Kids guidelines, which specify that no sodas, no snacks over 300 calories, and only all whole-grain cookies and snacks be made available to students. It also revealed that Louisa County was exceeding USDA recommendations by requiring that bread items on the breakfast and lunch menus contain at least 51 percent whole grains, that Greene County was offering one fresh vegetable option at lunch (in addition to a cooked vegetable), and that three Albemarle County elementary schools had individual (not county-supported) initiatives to establish school gardens.

Armed with this baseline information, students could then focus their community interviews more on exploring challenges and opportunities, allowing stakeholders sufficient time to share innovative ideas. Charlottesville stakeholders, for example, suggested the establishment of a nutrition advisory board run by students as a unique way to generate student-led discussion, recommendations, and action surrounding healthy eating in schools. Green County stakeholders suggested mandatory physical education classes for all grade levels, with gardening as an option, as gardening could also foster interest in agriculture among youth. They also suggested piggybacking on their county's popular annual arts festival to hold a concurrent health festival.

If a policy or program did not exist in the locality, students would record a "no" in the audit; however, during the community engagement portion of the audit, community members often had comments or questions about the subject matter of these audit questions. They might confirm the absence of a formal local policy or program, but inform the students of other kinds of community activities that were tackling the issue from a different angle.

For example, the Fluvanna County audit did not find formal county policies supporting food justice (see audit questions 70-105), but through community engagement the students learned that the county had developed an effective system to provide access to food for the elderly, disabled, and impoverished. In Nelson County, the audit did not find a formal policy addressing community health, and community engagement revealed that some local food traditions pose a major challenge. A heavy reliance on high-fat, high-cholesterol ingredients and cooking methods has led to significant county health challenges with obesity, diabetes, and high cholesterol affecting family members of all ages. The audit also indicated that introduction of new foods and cooking techniques to support personal health would be difficult, but could be effective if done through the schools in the form of family education workshops on healthy cooking and gardening. It is unlikely that Nelson County's challenge of food heritage, and the nuanced strategy for addressing it, could have been identified without the audit's community engagement phase.

The audit process of asking community stakeholders about their challenges and opportunities proved to be a powerful phase of the Food Policy Audit. Without this phase, the audit remains a simple research tool for collecting data. With this phase, the audit becomes a tool that enables deeper understanding of what is or isn't working in the local food system, and simple steps that might be taken to advance the local food system. In short, the community engagement phase transforms the audit into a tool that can motivate and empower people to effect change.

In Louisa County, it was the community engagement phase that caused community members to have a key insight: by simply expanding county van transportation for seniors and people with disabilities to the weekend, when the local farmers' markets are held, they would increase access among these populations to fresh, healthy food. Similarly, the county looked good in the research phase of the audit because of a comprehensive plan that suggested improving biking and pedestrian paths, especially "around schools and shopping centers." It was the community engagement phase that revealed that walking or biking to a grocery store is not feasible in most of rural Louisa, and that some sort of public 
transportation to groceries would be more helpful for most Louisa residents.

The final stage of the audit process called for distributing the student audit reports to all community members and government officials who had participated in the process. In addition, each student group presented their findings in a public forum. These presentations served to build understanding about community food systems in general, while also offering a "primer" on the current policies and priorities in each of the six localities.

Formally presenting the findings is another way that the audit process can be an important tool for change. In Nelson County, community participants were so motivated by the audit that they formed a task force to begin to implement the audit's findings and community recommendations. Following the formal presentation of the audit, one community stakeholder, an owner of a farm in Nelson County, sent the student audit report to fellow community members who had not been involved in the audit process. A number of these people decided they wanted to advance their community's priorities, as identified through the audit, which eventually led them to create the Nelson County Sustainable Food System Council. This council includes multistakeholder representation of seniors, school food services, food pantry (safety net), and elected board of supervisors. The council has since had multiple meetings and kicked off spring 2011 with some successful initiatives. As local farmer Gary Scott explained, "Our initial effort was to participate in the Farm to Schools Week; we had display materials and provided local food products each day of that week. I provided 85 pounds of broccoli and 33 pounds of cut lettuce. We got some good press and exposure including TV coverage." It was the audit process that provided the community with needed background data and also elicited appropriate and attainable goals from the community, thereby inspiring and empowering - community members to improve their local food system.

\section{Conclusions}

As food systems gain respect as an important focus for twenty-first century community planners, the tools used in the food planning process should evolve to best utilize the planner's skill set. To date, community food system assessments have served as the planner's main method for gauging a community's assets, gaps, opportunities, challenges, wants, and needs. The assessment process can be more effective when supplemented with a Food Policy Audit that identifies strengths and gaps in existing public health, economic development, environmental impacts, social equity, and land conservation policies. This model, developed and tested by the University of Virginia, is composed of an objective inventory of policies and initiatives in combination with community engagement to both authenticate the results and provide insight into community strengths, opportunities, and priorities.

Based on feedback from both students and an end-of-semester survey of community participants, the audit project was considered a positive experience by most. Community participants who were active in food system work indicated that the audit was a new and useful tool for analyzing policies and their applications, and resulted in a quick guide to components of an effective food system. Some community members expressed concern that the audit process did not provide more in-depth analysis of why certain policies did or did not exist, as well as analysis of what might be most helpful to the community. It is important to note that the tool itself does not inherently restrict deeper analysis. In the test run, analysis was constrained by a 14 -week semester that permitted only limited student community engagement. The authors of the FPA envision that, when used by professional planners or community citizen groups, this tool will initiate broader community engagement, deeper research, and more in-depth analysis.

Overall, the FPA process proved educationally beneficial to both students and community members, and the faculty team concluded that it does provide a comprehensive and useful policybased tool for communities interested in shaping a more sustainable and resilient food system. Through this pilot project, the team learned that the two phases of the tool are complementary and both are essential. More, the team also learned that the audit design — with community engagement 
focusing on identifying challenges, opportunities, and priorities - lays the groundwork for community action. Ideally, the whole process would span 10 months, as outlined in figure 1. The personal engagement of community stakeholders gives them both the information and space to think about their food system in new ways. The specificity of the audit's questions empowers stakeholders to think more strategically, inviting them to envision how their community food system could be improved with very specific policies.

The Food Policy Audit is a logical tool for communities wishing to develop a community food system strategic plan. It inventories all aspects of a community's food system policy and program infrastructure, ground-truths this research through interviews with key community stakeholders, and then identifies key community food system challenges, opportunities, and priorities. With these elements completed, a community would be poised to develop a draft strategic food system plan that could be vetted through a task force, focus groups, and community workshops. The strategic plan is more likely to reflect community values and garner community support because of the audit's comprehensive research and significant community involvement.

\section{Next Steps}

The faculty team has made the tool widely available for others to adapt or adopt for their own community purposes (Ray \& Denckla Cobb, 2010). The team posted the tool online and sent notices through a variety of listservs about its availability. It is included here in the appendix. The team has also responded to questions from local planners around the country who have expressed interest in using and/or adapting the tool for their local community. The faculty team sees this tool as a beginning point, not a finished product, and is eager to receive feedback from other communities that use or adapt it for their own purposes. Also, the faculty team envisions using the tool in future food system planning courses to conduct audits of other Virginia communities. As it does so, the team plans to continue perfecting the tool and updating the online template to reflect its latest thinking.

A helpful next step to improve the audit would be to develop a short citizens guide for conducting a Food Policy Audit. This guide should be written

\section{Figure 1. Food Policy Audit Process and Timeline}

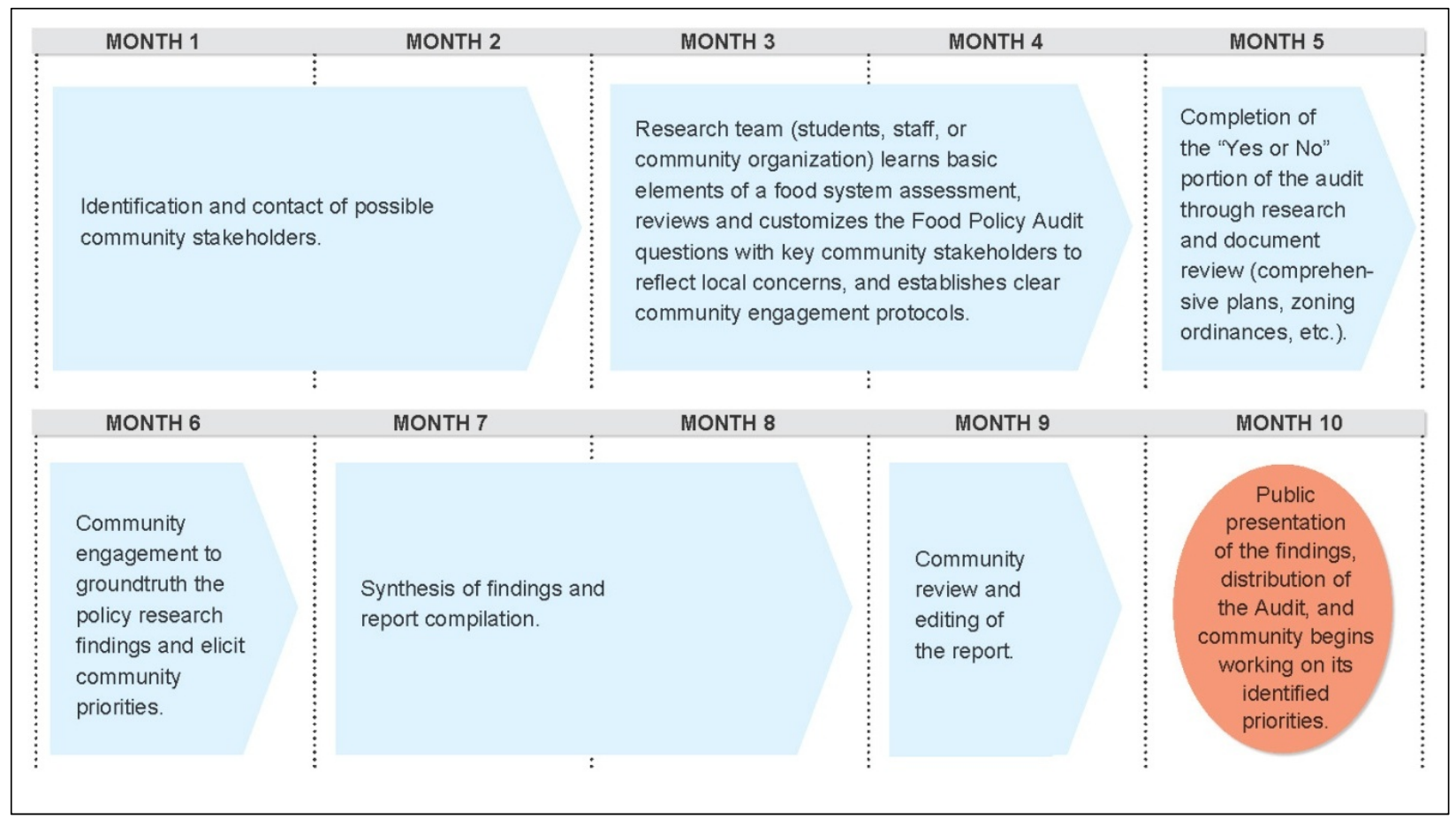


in a way that it can be used by community planners as well as by citizen leaders and nonprofit organizations that wish to take a lead in advancing their local community food system. The guide would provide step-by-step explanations, including best practices for both the research and community engagement phases. Lastly, in response to feedback received from community participants in our pilot audit, the guide ideally would provide guidance for deeper analysis during the research phase, so that the audit would not only identify what policies do or do not exist, but would also explicate the local history of why the locality's policies are shaped the way they are or, conversely, why the locality has not adopted specific policies. Such a guide would enable a wider distribution and more standardized use of the audit tool. Further, in an age of limited budgets and resources, a citizens guide would empower nonplanners, citizen leaders, and nonprofit organizations interested in their local food system to assist their community by undertaking an independent community Food Policy Audit. The audit may be lengthy, but it is not inherently difficult. Further, the audit could be accomplished by a collaboration among community organizations with differing expertise. For example, a community land trust might be asked to conduct the portion of the audit concerning land conservation, a local health organization the portion concerning public health and schools, and so forth. In this way, the audit would become a communitywide endeavor, building community interest and engagement at multiple levels.

Finally, after the audit is employed in a variety of communities, evaluation of the tool's efficacy would be another important next step. Freedgood, Pierce-Quiñonez, and Meter argue that assessment tools "would benefit from evaluation of the extent and efficacy of community engagement, the assessment's ability to unify stakeholders regarding a common agenda, and the impacts of the related food system work on the community defined" (2011, p. 100). For this tool, because of its very specific focus on existing policies and policy opportunities, it would be interesting also to evaluate the tool's efficacy of moving stakeholders beyond identification and prioritization of policy opportunities to successful initiation of changes in local policies. The tool would also benefit from a comparative evaluation of its efficacy in communities with different policy frameworks and demographics. We envision the Food Policy Audit as a flexible tool to engage the community and build consensus around policy needs and priorities for the food system. Through evaluation and adaptation, we hope that this tool will enable communities to shape and sharpen their policies to more effectively achieve their broader food system goals.

To access the Food Policy Audit, visit: http://www.virginia.edu/ien/foodplanning resources.htm\#2010

For questions about the tool, please contact Tanya Denckla Cobbattanyadc@virginia.edu or +1-434-924-1855,or

Tim Beatley at beatley@virginia.edu or +1-434-9246457.

\section{Acknowledgments}

The authors wish to acknowledge Timothy Beatley, Teresa Heinz Professor for Sustainable Communities at the University of Virginia Department of Urban and Environmental Planning, for his creative contribution to the field by suggesting the need for a Food Policy Audit; and Jessica Ray for her extensive foundational research in developing the first draft of the audit questions, her effective outreach to the community to identify willing participants in the trial run of the FPA, and her assistance to students throughout the semester in addressing and resolving unforeseen challenges.

\section{References}

APA. (2007, May). Policy guide on community and regional food planning. Retrieved from http://www.planning. org/policy/guides/adopted/food.htm

Christeson, W., Taggart, A. D., \& Messner-Zidell, S. (2010). Too fat to fight. Washington, D.C.: Mission: Readiness. http://cdn.missionreadiness.org/ MR Too Fat to Fight-1.pdf

Cohen, B. (2002). Community Food Security Assessment Toolkit (USDA Economic Research Service Report E-FAN No. 02-013). Retrieved from http://www.ers.usda.gov/publications/efan02013/ 
Dahlberg, K. (1994). Food Policy Councils: The experience of five cities and one county. Paper presented at the Joint Meeting of the Agriculture Food and Human Values Society and the Association for the Study of Food and Society, Tucson, Arizona.

Freedgood, J., Pierce-Quiñonez, M., \& Meter, K. A. (2011). Emerging assessment tools to inform food system planning. Journal of Agriculture, Food Systems, and Community Development, 2(1), 83-104. http://dx.doi.org/10.5304/jafscd.2011.021.023

Fromartz, S. (2006). Organic Inc.: Natural foods and how they grew. Orlando, Florida: Harcourt.

Pothukuchi, K. (2004). Community food assessment: A first step in planning for community food security. Journal of Planning Education and Research, 23(4), 356-377.

http://dx.doi.org/10.1177/0739456X04264908
Pothukuchi, K., Joseph, H., Burton, H., \& Fisher, A. (2002). What's cooking in your food system? A guide to community food assessment. Community Food Security Coalition. Available at http://foodsecurity.org/pub/whats cooking.pdf

Pothukuchi, K., \& Kaufman, J. L. (1999). Placing the food system on the urban agenda: The role of municipal institutions in food systems planning. Agriculture and Human Values, 16(2), 213-224. http://dx.doi.org/10.1023/A:1007558805953

Ray, J., \& Denckla Cobb, T. (2010). The Food Policy Audit. Available at the University of Virginia Institute for Environmental Negotiation website: http://www.virginia.edu/ien/ foodplanningresources.htm

Wolf, A., \& Colditz, G. (1998). Current estimates of the economic cost of obesity in the United States. Obesity Research, 6(2), 97-106. 


\section{Appendix. The Food Policy Audit Questions}

\section{Food Policy Audit Questions}

Auditors (graduate students, citizen volunteers, or planners) read their localities' comprehensive plans, zoning ordinances, regional and state guidelines, school programming and wellness policies, school district strategic plans and any other applicable governing documents, in search of policies or regulations that would effect the local food system. Specifically, they answer the following 113 questions while reviewing the documents and interviewing community members. The questions are divided into five categories: Public Health, Economic Development, Environmental Benefits, Social Equity, and Land Conservation / Access to Land for Food Production.

The results of this community research are recorded in the audit spreadsheet with a simple 'yes' or 'no.' If community planning documents or activities address the issue in question, auditors mark the spreadsheet with a 'yes,' and include document references and detailed explanations in an appendix. If neither planning documents or community activities address the issue, auditors mark the spreadsheet with a 'no.'

\section{PUBLIC HEALTH}

\section{a. Reduce and Prevent Community Obesity and Chronic IIness}

1. Does the locality express a concern or a goal for improving public health?

2. Does the locality mention a goal to reduce obesity and/or chronic illness?

3. Does the locality have an overall wellness plan?

4. Does the locality clearly allow, support, or advocate for Farm to Schoo (or similar) programs - for educational purposes, or for provision of food for school cafeteria?

5. Does the locality have other provisions for school purchasing of local or organic foods?

6. Does the locality clearly have a policy to reduce availability of junk food in schools and public buildings (e.g., vending machines and purchasing options)?

7. Do the schools have a policy or program to educate cafeteria workers on preparation of fresh, local food and/or nutrient-rich food?

8. Is the locality clearly encouraging or supporting the inclusion of food-based lesson plans in schools?

9. Does the locality clearly encourage and/or directly support establishment of school garden programs at all levels of K-12?

10. Is the locality currently employing or considering a "joint use" agreement to open the use of school land for food production (school gardens, community gardens, community urban farm)?

11. Does the locality encourage that chain restaurants provide consumers with calorie information on in-store menus and menu boards?

12. Does the locality have a clear tax or other strategy to discourage consump- tion of foods and beverages with minimal nutritional value, such as sugar sweetened beverages?

13. Does the locality have educational/ promotional programs to discourage the use of Supplemental Nutrition Assistance Program (SNAP) for sodas, high sugar and low nutrient foods?

\section{b. Engage public by increasing} awareness of healthy and local food options

14. Does the locality have a goal for increasing awareness of healthy food or lifestyle choices?

15. Has the locality adopted a clear policy defining "local" food?

16. Does the locality have a clear goal that supports the production and distribution of local food?

17. Does the locality publish or support a public guide to local food?

18. Does the locality have a clear policy of encouraging (or giving preference to) event caterers or vendors that will use locally sourced food?

19. Does the locality develop media campaigns, utilizing multiple media channels (print, radio, internet, television social networking, and other promotional materials) to promote healthy eating?

20 . Does the locality support or participate in a Food Policy Council?

\section{c. Flexible Policies and Zoning for} creative and adaptive uses

21 . Does the code allow for and support protection of open space?

22. Does the locality promote or enable easy accessibility to community gardens, for all neighborhoods and income levels?

23. Are there land protections for farmers markets?

24. Does the locality promote or enable easy, local access to community gardens by allowing small pocket parks throughout the locality to be used for, or transformed into community gardens?

25 . Does the code allow for temporary and conditional use of abandoned lots for neighborhood gardens and/or urban farms?

26 . Does the municipality work with an area community land trust in setting aside land for community? or nonprofit gardens? or gardens where low-income residents can grow produce for sale?

27 . Does the zoning code have language that supports residential "farm" animals; chickens, goats, roosters? (look for re-defining domestic animals)

28. Are there funding streams available for food related projects, such as Community Development Building Grants?

29. Are there regulations allowing $\mathrm{fl}$ exibility for food producers to engage in minimal on-site processing?

\section{d. Promote multi-modal transportation options to food sources}

30. Does the locality offer multi-modal transportation in the community?

31. Does the locality have a policy or programs to provide multimodal transportation options in the community to enable transportation of low-income populations to grocery stores? Does it reference or include transportation for migrant farm workers from camps?

32. Does the locality have a program that, alternatively, transports local produce to low-income neighborhoods and migrant farm worker camps? (e.g. trucks, food carts, etc.)

33. Do safe biking and walking paths exist between neighborhoods and food stores and markets?

34. Does the locality have a bus service that connects neighborhoods directly with food stores and markets? Requiring no more than one bus change? 
connects low-income neighborhoods directly with food stores and markets (requiring no more than one bus changes) for rural as well as urban areas?

72. Are transportation services available at multiple times of day and evening?

73. Has the locality done any infrastructure, transportation or other studies to identify issues of low-income neighborhoods gaining access to quality food, in rural as well as urban areas?

74. Do safe biking and walking paths exist between low-income neighborhoods and food stores and markets, in rural as well as urban areas?

75. Are farmer's markets geographically accessible by low income neighborhoods, in rural as well as urban areas?

b. Support location of grocers providing healthy local, foods in diverse and underserved locations

76 . Does the locality have an expedited development and/or permitting process for groceries that will provide healthy, local foods in underserved locations - in rural as well as urban areas?

77. Does the locality recognize through policy or programs the need for low income, immigrant populations, and migrant farm workers, to have access to grocers that provide local, fresh foods -in rural as well as urban areas?

78. Are tax credits available to developers for opening a grocery store in certain areas?

79. Are there any regulatory incentives, such as relaxed zoning requirements, faciliating new stores in underserved areas? 80 . Does the locailty offer any predevelopment assistance to developers to expedite the review process?

\section{c. Increase availability of fresh and healthful foods for underserved com- munities}

81. Does the locality support the purchase/ use of Electronic Benefit Transfer (EBT) cards to provide low-income access to farmer's markets?

82. Does the locality support the policy of $\$ 2$ or $\$ 3$ for every EBT dollar, when the EBT is used at farmer's markets or other market venues for fresh, local food?

83. Do farmer's markets and/or grocery stores accommodate WC coupons Senior Nutrition Coupons, or EBT machines?

84. Do farmer's markets enable $\$ 2$ or $\$ 3$ healthy food credit for every EBT dollar?
85. Are markets and stores accessible at multiple times and days to accommodate varying work schedules?

86. Does the locality support, or are there programs for mobile farms stands and mobile food carts?

87. Do local faith, nonprofi t organizations, and educational institutions (public and private) have policies to buy local food for events when available?

\section{d. Support an effective emergency food infrastructure}

88. Does the locality have a policy that its citizens have a "right to food security." (cf: Belo Horizonte, Brazil)

89. Does the locality support the provision of a central directory of all emergency food providers?

90 . Does the locality have a system for directing / referring people in need of food to the places that can help?

91. Does the locality support coordination and cooperation among emergency food providers?

92. Does the locality support a method, structure or storage facility for donations of fresh foods to emergency food providers?

\section{e. Support equitable working conditions} for farm labor

93. Does the locality support a living wage policy for all those who work including migrant farm labor?

94 . Does the locality support access to fresh, healthful food by the farm laborers who are helping to produce the food?

95 . Does the locality provide or ensure that training for farm workers is provided in a comfortable training environment, and that the training is adequate and in their native language, and that someone is available to answer farm worker questions in their own language?

96 . Does the locality provide or ensure that adequate protection against pesticides is provided to farm workers?

97. Does the locality have a program or support a program to encourage and enable transitional farm labor to become engaged in, or participate in, or become integrated into community events - such as through volunteering for county fairs, agricultural events?

98. Does the locality have a clear contact for migrant farm workers to contact, to participate in any aspect of the community?

99. Does the locality have a map of where farm worker camps are, to facilitate under- standing and planning for their needs? 100. Are housing options available for migrant workers?

f. Promote community involvement and ownership in local food system

101. Are community members involved in the organization of markets or other food opportunities?

102. Are culturally appropriate, fresh food options available for immigrant and ethnic populations in stores?

103. Is there support for diverse, local, traditional - and fresh - food practices?

104. Does the locality support or have a program to incorporate the participation of local migrant workers into local food farmers' markets and farm stands, to integrate and protect workers while they're in the community, as isolation is a major factor in migrant worker life? 105. Does the locality support or have a program to support agricultural opportunities for low income, immigrant and farm labor populations?

\section{LAND CONSERVATION / ACCESS TO LAND FOR FOOD PRODUCTION}

106. Does the locality have a policy to support land conservation for food production?

107. Does the locality encourage or support land conservation easements for food production?

108. Does the locality clearly allow the use of public space or land for nonprofit community food gardens?

109. Are there creative leasing or financing models to reduce start-up farming debt?

110. Does the locality have a map of its prime agricultural lands for conservation? 111. Does the locality have a map of prime agricultural lands that it wishes to conserve for food production, agri-tourism, heritage tourism, or other purposes supporting local food production.

112. Does the locality limit development potential in prime agricultural land through purchase of development rights, transfer of development rights establishment of agricultural districts, or through other means?

113. Does the locality have a green infrastructure plan that incorporates consideration for food production? 